\title{
Investigation of hybrid molecular material prepared by ionic liquid and polyoxometalate anion ${ }^{\dagger}$
}

\author{
T RAJKUMAR and G RANGA RAO* \\ Department of Chemistry, Indian Institute of Technology Madras, Chennai 600036 \\ e-mail: grrao@iitm.ac.in
}

\begin{abstract}
A solid hybrid molecular material containing 1-butyl 3-methyl imidazolium cations and Keggin anions of phosphotungstic acid has been synthesized. It is fully characterized by CHN analysis, FTIR, XRD, UV-Vis-NIR DRS, ${ }^{31}$ P MAS NMR, TGA and SEM. The FTIR spectrum of the compound shows the fingerprint vibrational bands of both Keggin molecular anions and imidazolium cations. The aromatic $\mathrm{C}-\mathrm{H}$ stretch region $\left(2700-3250 \mathrm{~cm}^{-1}\right)$ of imidazolium cation is split due to the interaction between the ring $\mathrm{C}-\mathrm{H}$ and bulky Keggin anion. The red-shift in the UV-Vis spectra and the downfield ${ }^{31} \mathrm{P}$ MAS NMR chemical shift also confirm the electrostatic interaction between the ions in the compound. Near IR spectral region (1000-2500 nm) shows the elimination of water in the compound which is hydrophobic.
\end{abstract}

Keywords. 1-Butyl 3-methyl imidazolium bromide; molecular material; phosphotungstic acid; near IR.

\section{Introduction}

Ionic liquids are gaining importance in the synthesis of hybrid materials. ${ }^{1}$ The 'ionic liquid' moniker is used for low melting point salts that contain organic cations. ${ }^{2}$ Most of these organic salts are fluids below the boiling point of water, often even lower than the room temperature. ${ }^{3}$ They exhibit fascinating range of properties which include non-volatility, high thermal stability, non-flammability, good electrical conductivity and wider electrochemical properties. ${ }^{3,4}$ They have been extensively used in the synthesis of novel hybrid materials. ${ }^{1,5-10}$ The most common ionic liquids (IL) employed are imidazolium, pyridinium derivatives, phosphonium and tetralkylammonium compounds. The room temperature ionic liquidity is achieved by tailoring cations and anions to disturb salt's normally highly crystalline nature. For example, the melting point of $\mathrm{NaCl}$ can be brought down from $803^{\circ} \mathrm{C}$ to $80^{\circ} \mathrm{C}$ by simply replacing sodium with bulky imidazolium cation (figure 1).

Recently, inorganic polyoxometalate anions with the Keggin structure have been employed with sodium cations to synthesize room temperature ionic liquids. ${ }^{11}$ Inorganic polyoxometalates are important class of solid acid catalytic materials with Brønsted

\footnotetext{
${ }^{\dagger}$ Dedicated to Prof. C N R Rao on his 75th birthday

*For correspondence
}

acidity. ${ }^{12-14}$ They contain Keggin anions such as $\mathrm{XM}_{12} \mathrm{O}_{40}^{n-}(\mathrm{M}=\mathrm{W}, \mathrm{Mo} ; \mathrm{X}=\mathrm{P}, \mathrm{Si})$ with the primary structure shown in figure 1 . The Keggin anions are interconnected by hydrogen-bonded water molecules (maximum 29) forming a secondary structure. These<smiles>CCCC[n+]1ccn(C)c1</smiles>

(a) BmImBr ionic liquid

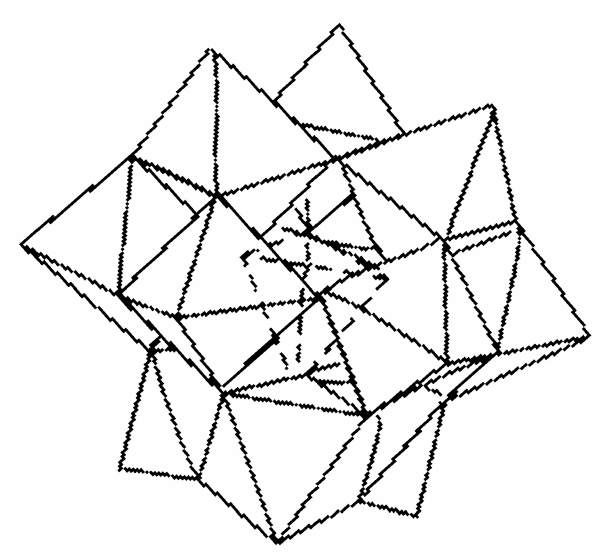

(b) The Keggin unit

Figure 1. (a) 1-Butyl 3-methyl imidazolium bromide (BmImBr), and (b) $\mathrm{PW}_{12} \mathrm{O}_{40}^{3-}$ Keggin molecular anion. 
large metal oxide framework anions (size $\sim 1 \mathrm{~nm}$ ) can react with variety of ionic liquids to form new ionic liquids ${ }^{7,11}$ and the corresponding organicinorganic hybrid molecular materials. ${ }^{9,10}$ The molecular materials containing organic cations bonded with bulky Keggin anions can find applications, for example, in photochromism ${ }^{15}$ and electrochemical systems. ${ }^{16,17,18}$ In this paper, we report the synthesis and characterization of molecular hybrid compound based on imidazolium cation and polyoxometalate Keggin anion. The molecular nature, morphology and thermal stability of the hybrid compound are examined by PXRD, TGA, FTIR, UV-Vis-NIR DRS, ${ }^{31} \mathrm{P}$ MAS NMR and SEM.

\section{Experimental}

\subsection{Synthesis of 1-butyl 3-methyl imidazolium bromide (BmImBr) ionic liquid}

All the starting materials were obtained from $\mathrm{M} / \mathrm{s}$ Fluka and used as received. The ionic liquid, 1-butyl 3-methyl imidazolium bromide, was synthesized in the laboratory using reported procedure. ${ }^{19}$ The IL was prepared by taking $1: 1$ mole ratio of 1-methyl imidazole and 1-bromobutane. In a typical preparation, $33.29 \mathrm{~g}$ of liquid 1-bromobutane was added to $20 \mathrm{~g}$ of liquid 1-methyl imidazole in a round bottomed flask fitted with reflux condenser under stirring conditions at $80^{\circ} \mathrm{C}$ for $24 \mathrm{~h}$. The top phase of the two phases formed contains unreacted starting material which can be removed by washing twice with ethyl acetate. This also ensures the removal of the unreacted material in the bottom phase containing IL product. The yellowish IL product of $\mathrm{BmImBr}$ liquid was further heated to $50^{\circ} \mathrm{C}$ to eliminate any dissolved ethyl acetate solvent and its formation was confirmed by IR, ${ }^{1} \mathrm{H}$ and ${ }^{13} \mathrm{C}$ NMR. ${ }^{20}$

\subsection{Synthesis of 1-butyl 3-methyl imidazolium phosphotungstate}

For the synthesis of 1-butyl 3-methyl imidazolium phosphotungstate salt, 1-butyl 3-methyl imidazolium bromide ionic liquid and aqueous solution of phosphotungstic acid $\left(\mathrm{H}_{3} \mathrm{PW}_{12} \mathrm{O}_{40} n \mathrm{H}_{2} \mathrm{O}\right)$ were taken in $3: 1$ mole ratio in order to prepare one mole of 1butyl 3-methyl imidazolium phosphotungstate. $3 \mathrm{~g}$ of 1-butyl 3-methyl imidazolium bromide was added drop-wise to the solution containing $14.3 \mathrm{~g}$ of phosphotungstic acid (PWA) under constant stirring at room temperature. The white precipitate obtained (product in scheme 1) was washed with distilled water until bromine free $\left(\mathrm{AgNO}_{3}\right.$ test $)$ and dried overnight at $80^{\circ} \mathrm{C}$.

The CHN analysis of the white colour solid shows that one mole of Keggin anions of $\mathrm{PW}_{12} \mathrm{O}_{40}^{3-}$ react with 3 moles of 1-butyl 3-methyl imidazolium cations to form the hybrid molecular material (scheme 1). The product dissolves in DMSO but not in water.

\subsection{Characterization}

All samples were analysed by X-ray diffraction employing Shimadzu XD-D1 diffractometer using $\mathrm{CuK}_{\alpha}$ radiation $(\lambda=1.5418 \AA)$. The IR spectra of different samples (as $\mathrm{KBr}$ pellets) were recorded using PerkinElmer infrared spectrometer with a resolution of $4 \mathrm{~cm}^{-1}$, in the range of $400-4000 \mathrm{~cm}^{-1}$. Thermo gravimetric analysis (TGA) of IL-PWA hybrid material was conducted in pure $\mathrm{N} 2$ gas ( $30 \mathrm{ml}$ per minute) at a heating rate of $20^{\circ} \mathrm{C}$ per min on a Perkin-Elmer TGA-7 instrument.

The UV-Vis-NIR spectra were recorded in diffuse reflectance mode on Jasco V-570 UV-Vis NIR spectrophotometer equipped with an integrating sphere in the spectral range of $200-2500 \mathrm{~nm}$. The spectra

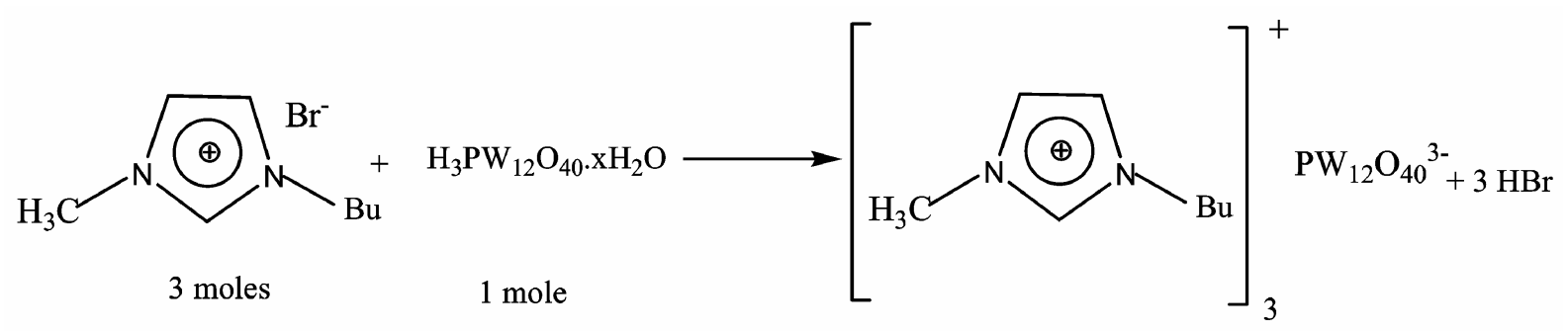

Scheme 1. 
are presented as Kubelka-Munk function $(\mathrm{F}(\mathrm{R}))$ versus incident photon wavelength. Scanning electron microscopy (SEM) images were taken using a FEI Quanta 200 microscope operating at $30 \mathrm{kV}$. The sample powders were deposited on a carbon tape before mounting on a sample holder.

The ${ }^{31}$ P MAS NMR spectra of PWA and IL-PWA hybrid material were recorded using Bruker Avance 400 spectrometer at resonance frequency of $161.97 \mathrm{MHz}$ for ${ }^{31} \mathrm{P}$ nuclei with Bruker CP MAS probe and the chemical shifts are reported in ppm $(\delta)$ relative to external $85 \mathrm{wt} \% \mathrm{H}_{3} \mathrm{PO}_{4}$. The ${ }^{31} \mathrm{P}$ MAS NMR spectra were recorded with a sample spinning rate of $8 \mathrm{kHz}$, and the delay between two pulses was $2 \mathrm{~s}$ for relaxation of the ${ }^{31} \mathrm{P}$ nuclei.

\section{Results and discussion}

\subsection{Powder XRD study}

In this work, we have substituted bulky anion $\mathrm{PW}_{12} \mathrm{O}_{40}^{3-}$ in place of $\mathrm{Br}^{-}$in the imidazolium based ionic liquid template. The pairing of Keggin anion with imidazolium cation has lead to the formation of organic-inorganic hybrid molecular solid. The formula estimated from the $\mathrm{C}-\mathrm{H}-\mathrm{N}$ elemental analysis of the sample is $\mathrm{C}_{24.90} \mathrm{H}_{41.93} \mathrm{~N}_{6 \cdot 23} \mathrm{PW}_{12} \mathrm{O}_{40}$ which gives an empirical structure of $\left[\left(\mathrm{C}_{8+x} \mathrm{~N}_{2} \mathrm{H}_{15-y}\right)_{3}\right]\left[\mathrm{PW}_{12} \mathrm{O}_{40}\right]$. The surface area of this white colour non-porous solid is $2.8 \mathrm{~m}^{2} \mathrm{~g}^{-1}$. Figure 2 shows the powder X-ray diffraction (PXRD) pattern of pure hydrated phosphotungstic acid and 1-butyl 3-methyl imidazolium phosphotungstate hybrid material, $[\mathrm{BmIm}]_{3}\left[\mathrm{PW}_{12} \mathrm{O}_{40}\right]$. The phosphotungstic acid undergoes structural transformation where three acidic protons and most of the $\mathrm{H}_{2} \mathrm{O}$ molecules are replaced by three 1-butyl 3methyl imidazolium cations. The PXRD pattern of $[\mathrm{BmIm}]_{3}\left[\mathrm{PW}_{12} \mathrm{O}_{40}\right]$ hybrid material is quite complex and reveals different structure compared to pure PWA salt. The PXRD pattern suggests that the phosphotungstic acid secondary structure is modified by the 1-butyl 3-methyl imidazolium cations since most of the sandwiched water molecules in the form of $\mathrm{H}_{3} \mathrm{O}^{+}$and $\mathrm{H}_{5} \mathrm{O}_{2}{ }^{+}$interacting with Keggin polyanions by hydrogen bonding are lost. ${ }^{12}$ This type of host-guest interactions are known to bring about the structural transformations which are detected by powder X-ray diffraction. ${ }^{21}$ The intense peak at $2 \theta=9.4$ in the PXRD pattern seems to indicate that the compound may have layered type of structure.

\subsection{FTIR study}

The FTIR spectra are quite useful to find structural and bonding changes in the Keggin unit present in 1butyl 3-methyl imidazolium phosphotungstate hybrid material, $[\mathrm{BmIm}]_{3}\left[\mathrm{PW}_{12} \mathrm{O}_{40}\right]$. The parent $\mathrm{PW}_{12} \mathrm{O}_{40}^{3-}$ Keggin structure shows characteristic $\mathrm{P}-\mathrm{O}$ stretching $\left(\sim 1083 \mathrm{~cm}^{-1}\right), \mathrm{W}-\mathrm{O}_{\text {terminal }}$ stretching $\left(\sim 987 \mathrm{~cm}^{-1}\right)$, stretching of $\mathrm{W}-\mathrm{O}_{\mathrm{c}}-\mathrm{W}$ inter bridges between cornersharing $\mathrm{WO}_{6}$ octahedra $\left(\sim 891 \mathrm{~cm}^{-1}\right)$, stretching of $\mathrm{W}-\mathrm{O}_{\mathrm{e}}-\mathrm{W}$ intra bridges between edge-sharing $\mathrm{WO}_{6}$ octahedra $\left(\sim 815 \mathrm{~cm}^{-1}\right)$ and $\mathrm{P}-\mathrm{O}$ bending $\left.\left(596 \mathrm{~cm}^{-1}\right)\right)^{13,14,22}$ In figure 3 , the IR spectrum of ILPWA is compared with the IR spectra of parent $\mathrm{BmImBr}$ and $\mathrm{H}_{3} \mathrm{PW}_{12} \mathrm{O}_{40} n \mathrm{H}_{2} \mathrm{O}$. The five prominent IR features due to $\mathrm{PW}_{12} \mathrm{O}_{40}^{3-}$. ion cluster in the hybrid material are clearly marked in the stretching region of $475-1120 \mathrm{~cm}^{-1}$ indicating that the primary Keggin structure is intact in the 1-butyl 3-methyl imidazolium phosphotungstate material. As reported by

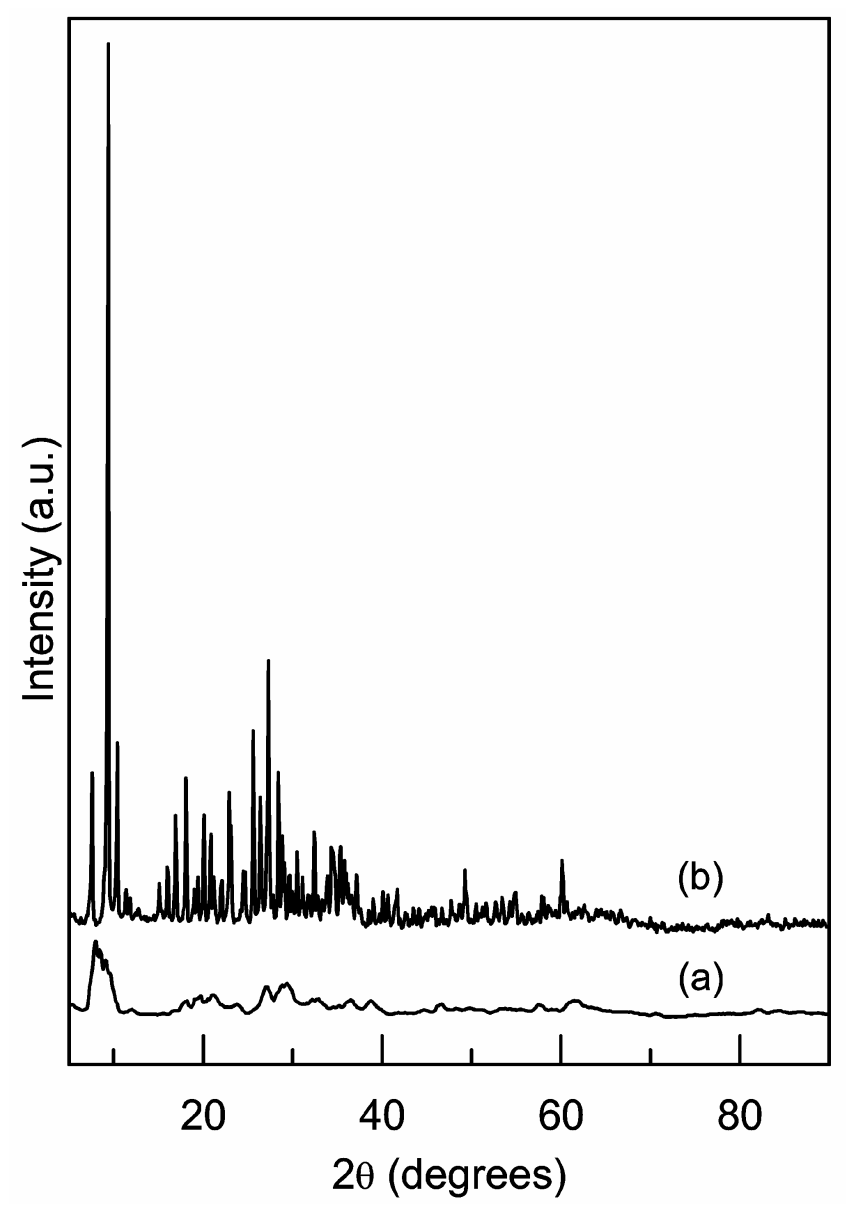

Figure 2. Powder XRD pattern of (a) $\mathrm{H}_{3} \mathrm{PW}_{12} \mathrm{O}_{40} n \mathrm{H}_{2} \mathrm{O}$, and (b) $[\mathrm{BmIm}]_{3}\left[\mathrm{PW}_{12} \mathrm{O}_{40}\right]$ hybrid molecular material. 




Figure 3. FTIR spectra of (a) 1-butyl 3-methyl imidazolium bromide (BmImBr) ionic liquid, (b) $\mathrm{H}_{3} \mathrm{PW}_{12} \mathrm{O}_{40} n \mathrm{H}_{2} \mathrm{O}$, and (c) $[\mathrm{BmIm}]_{3}\left[\mathrm{PW}_{12} \mathrm{O}_{40}\right]$ hybrid molecular material.

Table 1. IR data of $\mathrm{BmImBr}, \mathrm{H}_{3} \mathrm{PW}_{12} \mathrm{O}_{40} n \mathrm{H}_{2} \mathrm{O}$ and $[\mathrm{BmIm}]_{3}\left[\mathrm{PW}_{12} \mathrm{O}_{40}\right]$ hybrid molecular material.

\begin{tabular}{lccl}
\hline & Wavenumber $\left(\mathrm{cm}^{-1}\right)$ & \\
\cline { 1 - 2 } & PWA & {$[\mathrm{BmIm}]_{3}\left[\mathrm{PW}_{12} \mathrm{O}_{40}\right]$} & \multicolumn{1}{c}{ Vibration mode } \\
\hline 3450 & 3450 & - & Water in the material \\
3146,3090 & - & $3163,3146,3125,3114,3095$ & Imidazole ring $v(\mathrm{C}-\mathrm{H})$ \\
$2960,2936,2874$ & - & $2960,2936,2874$ & Aliphatic $v(\mathrm{C}-\mathrm{H})$ \\
1630 & 1630 & - & O-H bending \\
1570,1563 & - & 1570,1563 & Imidazole $-v(\mathrm{ring})$ \\
1168 & - & 1165 & Imidazole $\mathrm{H}-\mathrm{C}-\mathrm{C}$ and $\mathrm{H}-\mathrm{C}-\mathrm{N}$ bending \\
- & 1080 & 1080 & $v(\mathrm{P}-\mathrm{O})$ \\
- & 987 & 980 & $v\left(\mathrm{~W}=\mathrm{O}_{\text {ter }}\right)$ \\
- & 886 & 892 & $v\left(\mathrm{~W}-\mathrm{O}_{\mathrm{c}}-\mathrm{W}\right)$ \\
- & 810 & 807 & $v\left(\mathrm{~W}-\mathrm{O}_{\mathrm{e}}-\mathrm{W}\right)$ \\
840 & - & - & In-plane imidazole ring bending \\
752 & - & - & Out-of-plane $\mathrm{C}-\mathrm{H}$ bending of imidazole ring \\
650 & - & 620,624 & Imidazole $\mathrm{C}_{2}-\mathrm{N}_{1}-\mathrm{C}_{5}$ bending \\
\hline
\end{tabular}

$\mathrm{Wu}$ et $a l^{20} \mathrm{BmIm}^{+}$cation can be identified by the spectral features in the regions of $550-700 \mathrm{~cm}^{-1}, 1130$ $1800 \mathrm{~cm}^{-1}, 2800-3200 \mathrm{~cm}^{-1}$ and $3200-3800 \mathrm{~cm}^{-1}$ of the molecular compound (compare spectra (c) with (a) in figure 3). The IR peak assignments for the hybrid material containing 1-butyl 3-methyl imidazolium cations and $\mathrm{PW}_{12} \mathrm{O}_{40}^{3-}$ Keggin anions are given in table 1 . The IR analysis clearly shows that the basic structure and geometry of Keggin anion entrapped in the $\mathrm{BmIm}^{+}$cations are preserved in the hybrid molecular material but the water content $\left(3450 \mathrm{~cm}^{-1}\right)$ is reduced significantly. ${ }^{20}$

A closer examination of IR spectra in the imidazolium ring $\mathrm{C}-\mathrm{H}$ stretch $\left(3000-3250 \mathrm{~cm}^{-1}\right)$ and imidazolium ring stretch $\left(1500-1620 \mathrm{~cm}^{-1}\right)$ in figure 4 reveals that there is a strong electrostatic interaction 
between $\mathrm{BmIm}^{+}$cation and large Keggin anion. Due to this interaction, the two $\mathrm{C}-\mathrm{H}$ stretching peaks of the imidazolium ring in $\mathrm{BmImBr}$ are split into five vibrational peaks in the $[\mathrm{BmIm}]_{3}\left[\mathrm{PW}_{12} \mathrm{O}_{40}\right]$ hybrid molecular salt. The imidazolium ring vibration is also split with intensity variations (figure $3 \mathrm{c}$ ). The origin of such $\mathrm{C}-\mathrm{H}$ split is clearly attributed to specific interaction of BmIm cation with bulky Keggin anion. ${ }^{9,10}$ This type of interactions leading to $\mathrm{C}-\mathrm{H}$ split have been reported in ionic compounds such as MPIm ${ }^{+} \mathrm{I}_{x}^{-23-25}$

\subsection{TG analysis}

The thermogravimetric behaviour of 1-butyl 3methyl imidazolium phosphotungstate hybrid material is shown in figure 5. The TGA curve indicates weight loss regions at (i) 140 to $250^{\circ} \mathrm{C}$, (ii) 250 to $420^{\circ} \mathrm{C}$, (iii) above $420^{\circ} \mathrm{C}$. The initial low temperature TG loss is due to small amounts of water present in the sample. The weight loss observed between 250 to $420^{\circ} \mathrm{C}$ is primarily due to the beginning of the decomposition of BmIm organic moiety. The pure

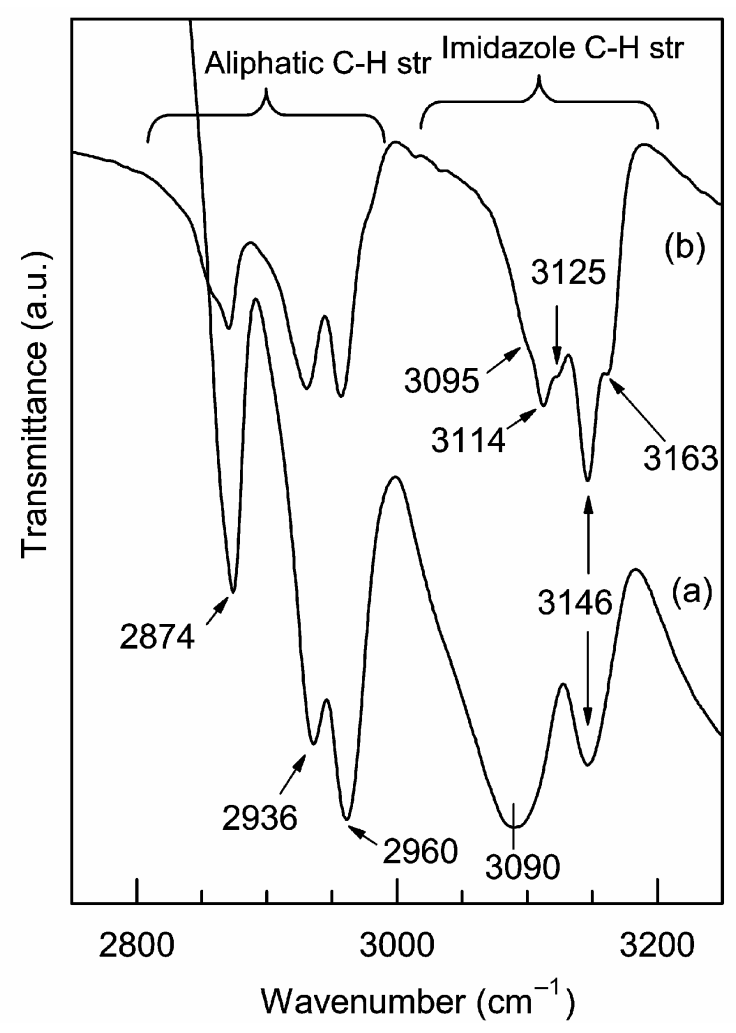

Figure 4. The $\mathrm{C}-\mathrm{H}$ stretch region of (a) 1-butyl 3methyl imidazolium bromide ionic liquid, (b) $[\mathrm{BmIm}]_{3}$ $\left[\mathrm{PW}_{12} \mathrm{O}_{40}\right]$ hybrid molecular material.
PWA is known to decompose at $550^{\circ} \mathrm{C},{ }^{14}$ and the weight loss in TGA curve above $420^{\circ} \mathrm{C}$ indicates a shift in the decomposition temperature of the Keggin ions attached to imidazolium rings. The rapid weight loss above $420^{\circ} \mathrm{C}$ is mainly due to the decomposition of Keggin units to $\mathrm{WO}_{3}$ and $\mathrm{P}_{2} \mathrm{O}_{5}$. The thermal stability and also the Bronsted acidity of the Keggin units have been affected due to their interaction with $\mathrm{BmIm}^{+}$moieties in the molecular hybrid material.

\section{$3.4 \quad U V$-Vis DRS and ${ }^{31} P$ MAS NMR studies}

The UV-Vis DR spectra of IL-PWA hybrid material recorded using integrating sphere are shown in figure 6 . The heteropolyacids in their non-reduced form are generally characterized by oxygen-to-metal $(\mathrm{O} \rightarrow \mathrm{M})$ charge transfer bands which appear in the UV region below $400 \mathrm{~nm}$. ${ }^{910,14,15,26}$ When hybrid materials based on heteropolyacids are irradiated with UV light, electrons are excited from the lowenergy electronic states (mainly oxygen $2 p$ orbitals in heteropoly anions) to the high-energy states (mainly metal $d$ orbitals). The electronic spectroscopy study of the phosphotungstic acid $\left(\mathrm{H}_{3} \mathrm{PW}_{12} \mathrm{O}_{40} n \mathrm{H}_{2} \mathrm{O}\right)$ shows three absorption bands at 220, 260 and $310 \mathrm{~nm}$ due to charge transfer transitions in the Keggin units (figure 6a) while $\mathrm{BmImBr}$ ionic liquid does not show any electronic transitions in the region (figure $6 b)$. The absorption band at $220 \mathrm{~nm}$ is most likely to

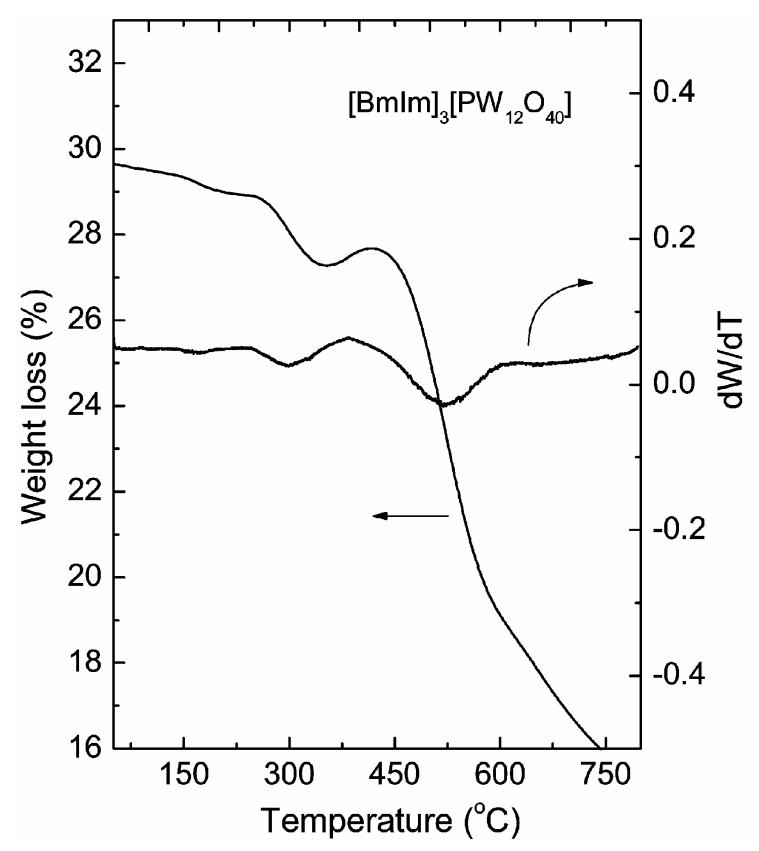

Figure 5. TGA of $[\mathrm{BmIm}]_{3}\left[\mathrm{PW}_{12} \mathrm{O}_{40}\right]$ hybrid molecular material. 
be due to $\mathrm{O} \rightarrow \mathrm{P}$ transition. The other two absorption bands correspond to the ligand to metal charge transfer $\left(\mathrm{O}^{2-} \rightarrow \mathrm{W}^{6+}\right)$ in the Keggin units, and interpreted as charge transfer absorptions where $\mathrm{W}$ atoms are located in $\mathrm{W}-\mathrm{O}_{\mathrm{e}}-\mathrm{W}$ intra bridges between edgesharing $\mathrm{WO}_{6}$ octahedra $(260 \mathrm{~nm})$, and $\mathrm{W}-\mathrm{O}_{\mathrm{c}}-\mathrm{W}$ inter bridges between corner-sharing $\mathrm{WO}_{6}$ octahedra $(310 \mathrm{~nm}) .{ }^{14}$ However, in the IL-PWA hybrid material the transition at $311 \mathrm{~nm}$ is shifted to $295 \mathrm{~nm}$ while the other two transitions remain at the same energy (figure 6c). This provides an evidence for the intermolecular electronic interactions between the 1butyl 3-methyl imidazolium cations and the Keggin anion. There are no additional transitions seen in the DR spectrum of 1-butyl 3-methyl imidazolium phosphotungstate hybrid material since the compound is white, like its parent compound $\mathrm{H}_{3} \mathrm{PW}_{12} \mathrm{O}_{40} n \mathrm{H}_{2} \mathrm{O}$.

Figure 7 shows the ${ }^{31} \mathrm{P}$ MAS NMR spectra of phosphotungstic acid and its hybrid material formed with ionic liquid. As reported, pure phosphotungstic acid shows a sharp and symmetric resonance peak at $-15.1 \mathrm{ppm}$ characteristic of phosphorous in the tetrahedral position of the Keggin unit. ${ }^{12-14}$ This resonance peak has been shifted to $-11.5 \mathrm{ppm}$ in the ILPWA hybrid material which is again a clear indica-

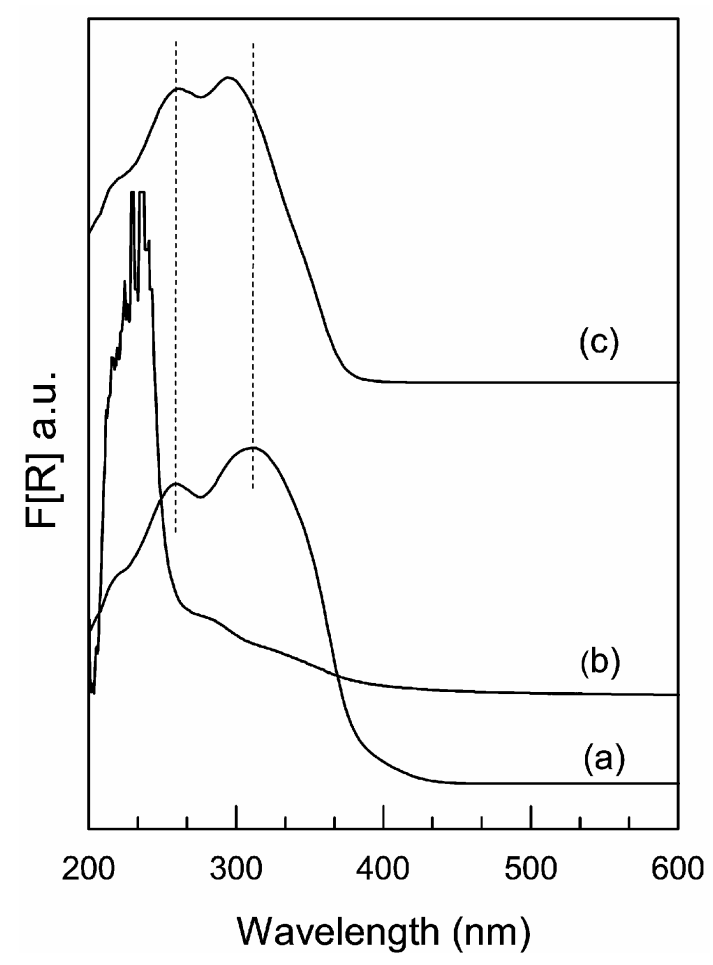

Figure 6. UV-Vis DR spectra of (a) $\mathrm{H}_{3} \mathrm{PW}_{12} \mathrm{O}_{40} n \mathrm{H}_{2} \mathrm{O}$, (b) $\mathrm{BmImBr}$ solution, and (c) $[\mathrm{BmIm}]_{3}\left[\mathrm{PW}_{12} \mathrm{O}_{40}\right]$ hybrid molecular material. tion of strong interaction between 1-butyl 3-methyl imidazolium cation and Keggin anions in the compound. The ${ }^{31} \mathrm{P}$ chemical shift is consistent with the UV-Vis DRS result discussed earlier. However, the downfield shift in ${ }^{31} \mathrm{P}$ MAS NMR of phosphotungstic acid can also occur due to the loss of water molecules from bulk material. ${ }^{12}$ This aspect is discerned clearly in near IR study in the next section.

\subsection{Near IR study and SEM study}

Near IR spectroscopy is used to detect water content in $\mathrm{H}_{3} \mathrm{PW}_{12} \mathrm{O}_{40} n \mathrm{H}_{2} \mathrm{O}$ and IL-PWA hybrid material by studying overtones and combination bands of the fundamental stretching frequencies of $\mathrm{H}_{2} \mathrm{O}$., 10,27,28 The near IR spectra of parent $\mathrm{H}_{3} \mathrm{PW}_{12} \mathrm{O}_{40} n \mathrm{H}_{2} \mathrm{O}$ and the IL-PWA hybrid materials are recorded by diffuse reflectance mode in the range of 1200 to $2500 \mathrm{~nm}$, which are shown in figure 8 . The three prominent bands observed at 1462, 1956 and $2252 \mathrm{~nm}$ in the near IR spectrum show the presence of water and hydroxyl groups in $\mathrm{H}_{3} \mathrm{PW}_{12} \mathrm{O}_{40} n \mathrm{H}_{2} \mathrm{O}$. These bands are attributable to the first overtone of hydroxyl groups, $\left(2 v_{\mathrm{O}-\mathrm{H}}\right)$, combination band corresponding to hydroxyl stretching and bending, $\left(v_{\mathrm{O}-\mathrm{H}}+\delta_{\mathrm{H}_{2} \mathrm{O}}\right)$, and

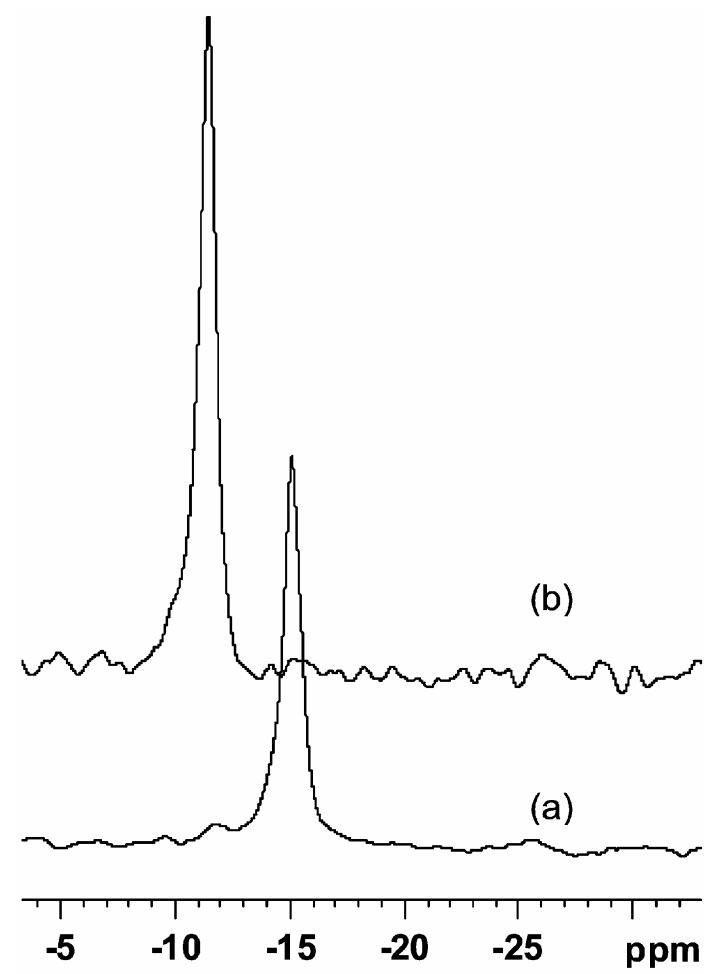

Figure 7. ${ }^{31} \mathrm{P}$ MAS NMR spectra of (a) $\mathrm{H}_{3} \mathrm{PW}_{12} \mathrm{O}_{40} n$ $\mathrm{H}_{2} \mathrm{O}$, and (b) $[\mathrm{BmIm}]_{3}\left[\mathrm{PW}_{12} \mathrm{O}_{40}\right]$ hybrid molecular material. 
combination band of $\left(v_{\mathrm{O}-\mathrm{H}}+\delta_{\mathrm{O}-\mathrm{H}}\right)$ vibrational modes, respectively. All these characteristic overtones and combination bands due to $\mathrm{H}_{2} \mathrm{O}$ are absent in the IL-

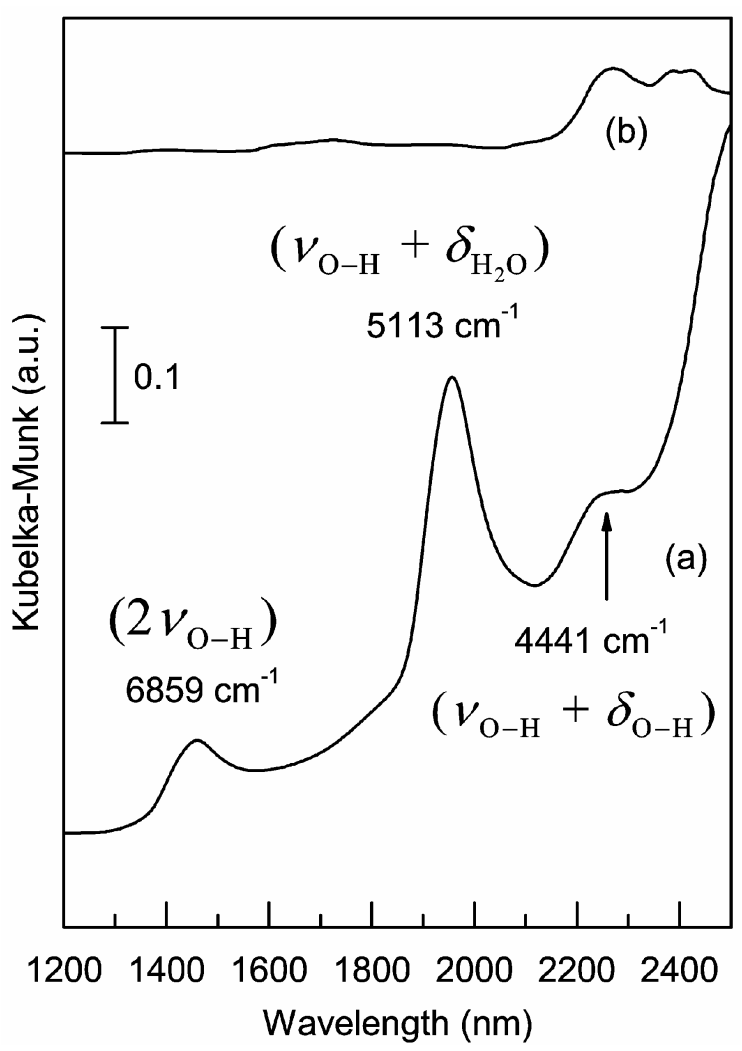

Figure 8. Near IR spectra of (a) $\mathrm{H}_{3} \mathrm{PW}_{12} \mathrm{O}_{40} n \mathrm{H}_{2} \mathrm{O}$, and (b) $[\mathrm{BmIm}]_{3}\left[\mathrm{PW}_{12} \mathrm{O}_{40}\right]$ hybrid molecular material.

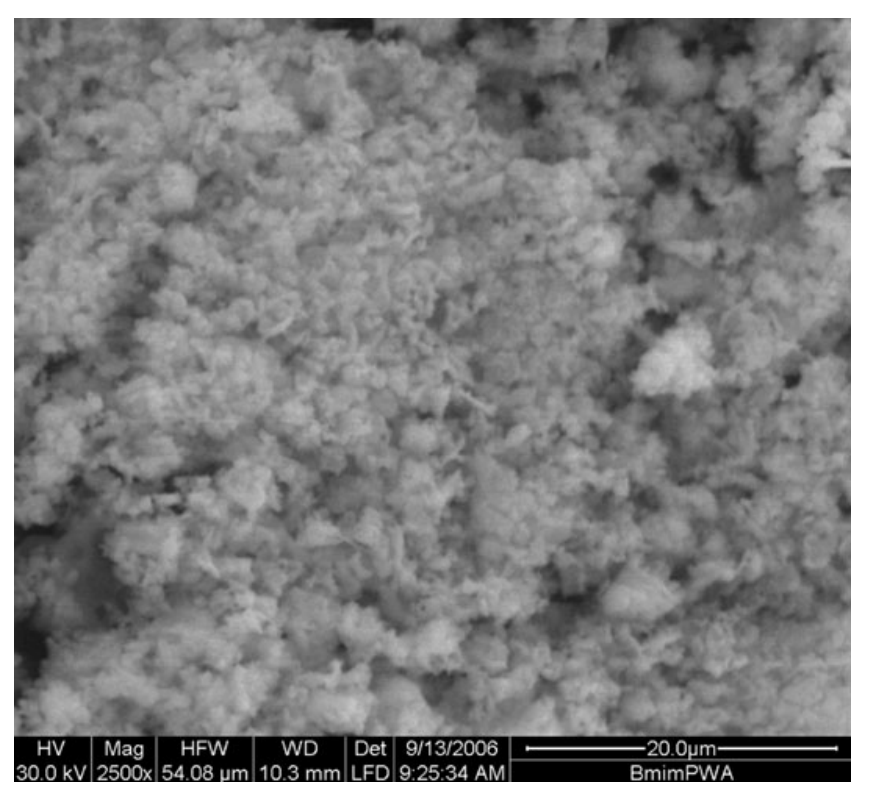

Figure 9. SEM image of $[\mathrm{BmIm}]_{3}\left[\mathrm{PW}_{12} \mathrm{O}_{40}\right]$ hybrid molecular material.
PWA hybrid material (figure $8 \mathrm{~b}$ ). The characteristic IR peak at $1620 \mathrm{~cm}^{-1}$ due to water is also very weak in the IR spectrum of the hybrid material (figure 3c). This confirms the elimination of water molecules associated with PWA when reacted with the BmIm cations forming the IL-PWA hybrid molecular material.

The morphgology of the hybrid material has been studied by SEM and the image obtained for 1-butyl 3 -methyl imidazolium phosphotungstate hybrid material at $2500 \times$ magnification is shown in figure 9 . The SEM topography of the powder reveals clusters of irregular shape and thread-like particles of about micron size present in the sample.

\section{Conclusions}

The $[\mathrm{BmIm}]_{3}\left[\mathrm{PW}_{12} \mathrm{O}_{40}\right]$ hybrid material formed by the reaction between 1-butyl 3-methyl imidazolium bromide ionic liquid and phosphotungstic acid has been fully investigated. This is a solid material with melting point $\sim 400^{\circ} \mathrm{C}$. IR spectrum shows the presence of both 1-butyl 3-methyl imidazolium cations and Keggin anions. The spectral shifts in UV-Vis DRS and ${ }^{31} \mathrm{P}$ MAS NMR, and the ring $\mathrm{C}-\mathrm{H}$ split in IR confirm strong interactions between the organic moiety and the Keggin species in the material. The hybrid material is hydrophobic and has no water content as determined by the near IR spectra.

\section{Acknowledgment}

We thank the Defence Research and Development Organisation (DRDO), New Delhi, for the research grant No.ERIP/ER/0300231/M/01/791.

\section{References}

1. Rao C N R, Cheetham A K and Thirumurugan A 2008 J. Phys.: Condens. Matter. 20083202

2. Wilkes J S 2002 Green Chem. 473

3. Seddon K R 1997 J. Chem. Tech. Biotechnol. 68351

4. Endres F and Abedin S Z E 2006 Phys. Chem. Chem. Phys. 82101

5. Nakashima T and Kimizuka N $2003 \mathrm{~J}$. Am. Chem. Soc. 1256386

6. Lee B, Luo H, Yuan C Y, Lin J S and Dai S 2004 Chem. Commun. 240

7. Rickert P G, Antonio M R, Firestone M A, Kubatko K A, Szreder T, Wishart J F and Dietz M L $2007 \mathrm{~J}$. Phys. Chem. B111 4685

8. Dong W S, Li M Y, Liu C, Lin F and Liu Z $2008 J$. Colloid Interface Sci. 319115 
9. Ranga Rao G, Rajkumar T and Varghese B 2008 Solid State Sci. (in print) doi:10.1016/J. solidstatesciences.2008.05.017

10. Rajkumar T and Ranga Rao G 2008 Mater. Chem. Phys. 112853

11. Dai L, Yu S, Shan Y and He M 2004 Eur. J. Inorg. Chem. 237

12. Misono M 2001 Chem. Comm. 1141

13. Ranga Rao G and Rajkumar T 2008 Catal. Lett. 120 261

14. Ranga Rao G and Rajkumar T 2008 J. Colloid Interface Sci. 324134

15. Gamelas J A F, Cavaleiro A M V, Gomes E D, Belsley M and Herdtweck E 2002 Polyhedron 21 2537

16. Chiang M, Dzielawa J A, Dietz M L and Antonio M R $2004 J$. Electroanal. Chem. 56777

17. Li Z, Zhang Q, Liu H, He P, Xu X and Li J 2006 J. Power Sources 158103

18. Kim J, Hayashi S, Mori T and Honma I 2007 Electrochimica Acta $\mathbf{5 3} 963$
19. Huddleston J G, Visser A E, Reichert W M, Willauer H D, Broker G A and Rogers R D 2001 Green Chem. 3156

20. Wu W, Li W, Han B, Zhang Z, Jiang $T$ and Liu $Z$ 2005 Green Chem. 7701

21. Choi E, Park K, Yang C, Kim H, Son J, Lee S W, Lee Y H, Min D and Kwon Y 2004 Chem. Eur. J. 105535

22. Deltcheff C R, Fournier M, Franck R and Thouvenot R 1983 Inorg. Chem. 22207

23. Yokozeki A, Kasprzak D J and Shiflett M B 2007 Phys. Chem. Chem. Phys. 95018

24. Jerman I, Jovanovski V, Vuk A Šs, Hočevar S B, Gaberšček M, Jesih A and Orel B 2008 Electrochim. Acta 532281

25. Jeon Y, Sung J, Seo C, Lim H, Cheong H, Kang M, Moon B, Ouchi Y and Kim D 2008 J. Phys. Chem. B112 4735

26. He T and Yao J 2006 Prog. Mater. Sci. 51810

27. McClure W F 2003 J. Near Infrared Spectrosc. 11 487

28. Mishra B G and Ranga Rao G 2006 J. Mol. Catal. A: Chem. 243204 